\title{
Board 46: The Mentoring Network of K-5 Educators and Engineering Re- searchers in an RET
}

\section{Ms. Gayle Nelson Evans, University of Florida}

Gayle Evans is a Lecturer and doctoral candidate in Curriculum \& Instruction, Science Education in the School of Teaching and Learning at the University of Florida. She is science coordinator for the UFTeach undergraduate secondary STEM teacher preparation program and previously worked as a high school science teacher. Her research interests include mentoring relationships and program development in STEM teacher preparation and professional development.

\section{Dr. Kent J. Crippen, University of Florida}

Kent Crippen is a Professor of STEM education in the School of Teaching and Learning at the University of Florida and a Fellow of the American Association for the Advancement of Science. His research involves the design, development, and evaluation of STEM cyberlearning environments as well as scientistteacher forms of professional development. Operating from a design-based research perspective, this work focuses on using innovative, iterative and theoretically grounded design for the dual purpose of addressing contemporary, complex, in situ learning problems while concurrently generating new theoretical insight related to the process of learning and the relationships among the people, tools and context of the problem space.

\section{Prof. Chelsey S Simmons, University of Florida}

Chelsey S. Simmons, Ph.D., joined UF in Fall 2013 following a visiting research position at the Swiss Federal Institute of Technology (ETH) Zurich. Simmons received her B.S. cum laude from Harvard University and her M.S. and Ph.D. from Stanford University. Her research lab investigates the relationship between cell biology and tissue mechanics, and their projects are funded by the National Science Foundation, National Institutes of Health, and American Heart Association. She has received numerous fellowships and awards, including NIH's Maximizing Investigators' Research Award for Early Stage Investigators (2018), BMES-CMBE's Rising Star Award (2017), ASME's New Faces Award (2015) and an NSF Graduate Research Fellowship as a student. She teaches undergraduate Mechanics of Materials and graduate BioMEMS courses and was named MAE Teacher of the Year in 2017.

In addition to her engineering research and teaching, Simmons leads a \$600k NSF-funded professional development program for elementary educators. Her efforts are bolstered by a legacy of education training and leadership, having received a Ph.D. Minor in Education and working as a founding officer and President of Stanford's American Society for Engineering Education.

\section{Dr. Renee Natalie Simmons}




\title{
The Mentoring Network of K-5 Educators and Engineering Researchers in a RET
}

\author{
Gayle Evans', Kent Crippen', Chelsey Simmons², Renee Simmons' \\ ${ }^{1}$ School of Teaching and Learning, University of Florida, ${ }^{2}$ Department of Mechanical \& Aerospace \\ Engineering, University of Florida
}

\section{Introduction}

Research Experience for Teachers programs (RET) are an established form of professional development for K-12 teachers in which they are invited to work as members of a laboratory research team in order to increase their enthusiasm, knowledge and experience in STEM fields. Historically, bringing teachers and scientists together in such a collaborative environment has taken several forms, from single or multi day workshops [1] or residential multi week programs [2], to commitments of a year or longer [3]. There are currently RET sites in Engineering and Computer Science that are actively funded by the National Science Foundation (NSF) in thirty-five states and the District of Columbia [4]. This form of professional development is recognized as a scientist-teacher partnership, defined by [5] as "collaboration among a group of college or university scientists and $\mathrm{K}-12$ teachers, with the goal of improving science education along the kindergarten through postgraduate educational continuum..." (p. 195). The inclusion of postgraduate education as part of this definition and inherent focus for such programs suggests the potential for positive outcomes for higher education participants as well as K-12 teachers.

Research has shown that participation in a RET can enhance teachers' definitions and enactments of inquiry-based teaching [6], foster collaboration among teachers, increase their motivation to incorporate the engineering design process into their lessons and increase content knowledge in engineering [7]. After participating in a RET, elementary teachers have reported a higher likelihood of incorporating experiments and collaborative activities into their lessons, and increased self-confidence about teaching science [8]. However, only one study has documented the potential benefits to scientists. [9] found that scientists, including doctoral students and post-doctoral researchers, learned new ways to interact with colleagues, improved their interpersonal skills, and expanded their knowledge of career opportunities related to teaching. In addition, they cited an improved ability to communicate research to non-scientists, greater confidence and qualifications for seeking a faculty position, and a realization of their role as role model. Such evidence suggests an unexplored, bi-directional relationship among all participants in a RET research laboratory.

Using developmental network theory, a framework that recognizes the potential for mentoring to involve multiple mentors and for each relationship to be bidirectional in its forms of support, this study sought to characterize the relationships among participants working in a newly established engineering RET for elementary teachers. Secondarily, we are reporting on our development of a unique mixed methodological approach that involves the use of social network analysis.

\section{Project Background}

The Engineering for Biology: Multidisciplinary Research Experiences for Teachers of Elementary Grades (MRET) was a 7-week summer program in which elementary teachers, individuals who teach kindergarten through grade five, were embedded as contributing members of engineering laboratory research teams. The project was established with the following goals: (1) increasing teacher knowledge of STEM 
concepts and practices, (2) fostering mentoring relationships among researchers and teachers in each laboratory, and (3) guiding the translation of the teachers' laboratory experience into the classroom through the development of STEM learning units (Figure 1).
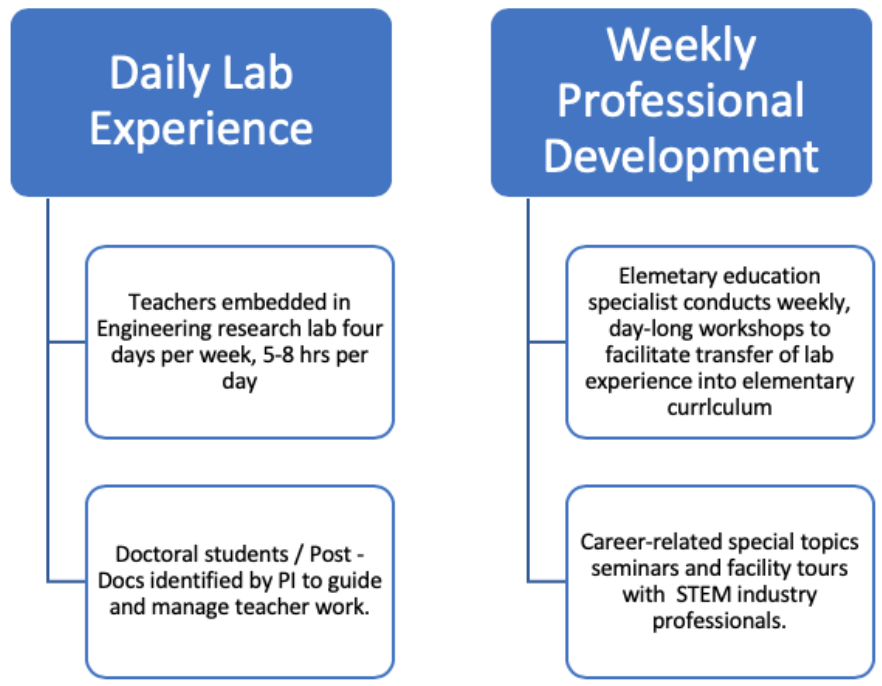

Figure 1: Concept design for the MRET summer components.

This study focuses on the second goal, and involves the use of developmental network theory to discriminate mentoring among participants within the summer 2017 and 2018 cycles of MRET.

\section{Theoretical Framework and Related Empirical Studies}

Developmental Network Theory was described by [10] building upon [11]'s observation that successful workplace mentoring relationships were more complex than the traditional paradigm of mentor-protégé dyads. Mentors are recognized as providing support in two different forms, psychosocial and career (Figure 2). Instead of a clear unidirectional flow of support and information from a single, more senior or experienced, "developer" to a less experienced, or younger "protégé," [10] described "constellations" (p.264) of relationships forming around a focus person / protégé. These networks were further typified through a comparison of the diversity and strength of the interactions among the people in a network. [12] suggest a general methodology for assessing mentoring from the developmental network perspective. 


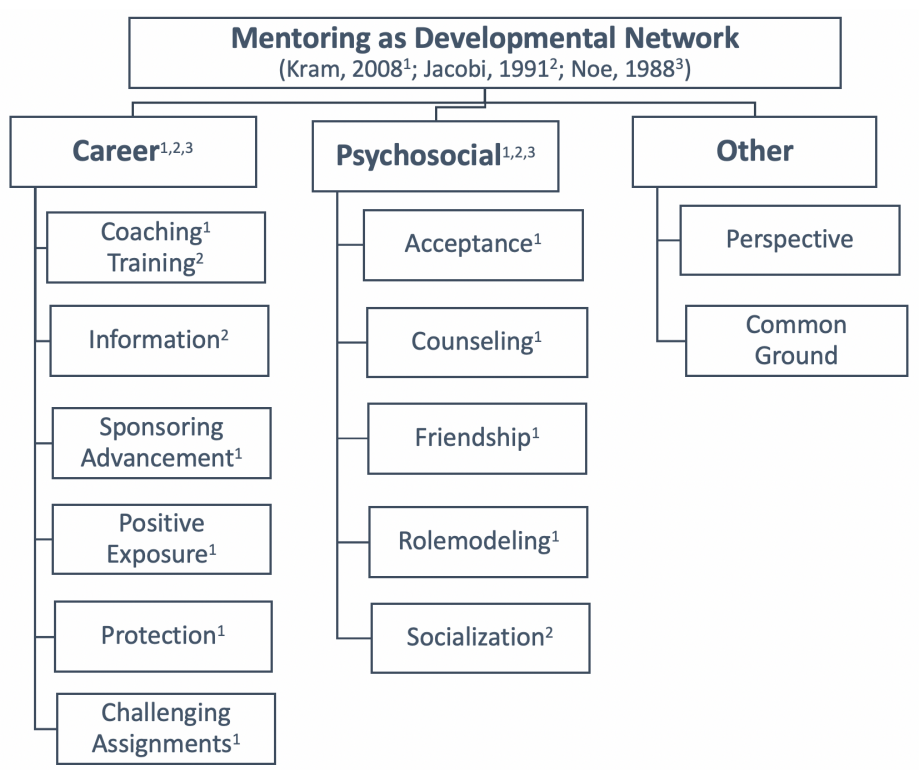

Figure 2. The categories of support and associated mentoring functions.

Although mentoring is widely viewed as a valuable type of relationship in fostering both career related and psychosocial development in its participants, it has proven to be difficult to define [13]. A traditional perspective on mentoring typifies the relationship as "one in which a senior person working in the protégé's organization assists with the protégé's personal and professional development" [11] (p. 265). Within the business world, however, an alternate typology of mentoring has been described in which a protégé will form constellations of relationships with people taking an active interest in their development [10],[11],[12].

In the published literature, mentoring is consistently recognized as a key element in cultivating successful scientist-teacher partnerships. [2],[3],[7]. One RET study found that building a science network was reported by teachers as a most valuable experience [8]. In addition, research findings support the importance of mentored laboratory experiences for development of novice scientists [14].

\section{Methodology}

This study involves two-cycles of an explanatory sequential mixed methods investigation encompassing two-years of an RET involving K-5 educators and engineering researchers [15].
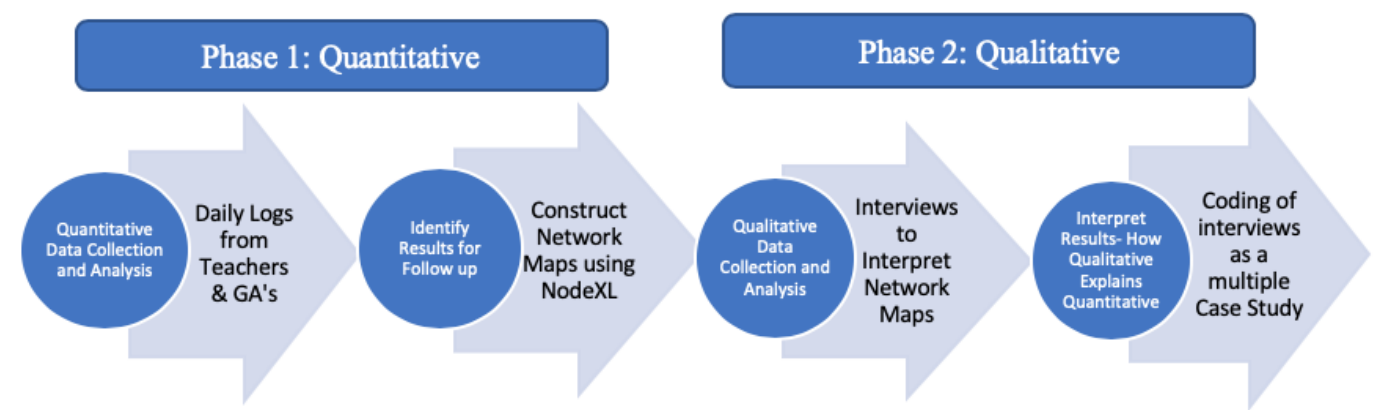

Figure 3: The Explanatory sequential model of mixed methods investigation used in this study.

Participants included pairs of teachers, each assigned to a pair of ENG graduate student researchers (henceforth, GAs) (Table 1). A coupled pair of teachers and pair of GAs worked collaboratively in a 
laboratory that was sponsored by a Principal Investigator (PI). The GAs were existing members of each laboratory group and were working full-time under the direction of the PI.

Table 1. Overview of the participants.

\begin{tabular}{|l|r|r|}
\hline & 2017 & 2018 \\
\hline Elementary Teachers & 6 & 12 \\
\hline GA's & 6 & 11 \\
\hline PI's & 3 & 6 \\
\hline TOTAL & 15 & 29 \\
\hline
\end{tabular}

Social interactions were captured in a series of daily activity and interaction logs submitted by all participants during a six-week program in which teachers were embedded in engineering research labs, and mentored by GAs, to serve as contributing members of the laboratory research team. Guided by developmental network theory, as described by [10], [12] and the "checklist of questions for designing a survey study plan" [15](p. 148), daily surveys were constructed in which participants were asked to report the following information about that day's experience in the lab:

(1) Activity log asking each teacher to describe the work they did that day in the lab, how engaged they were and how confident they felt in that work. GA's were asked to report the work and engagement level of the teacher pair, and to report how satisfied they were with the work of the teachers that day.

(2) Interaction Log asking each person to select from a list of all people in their laboratory, with whom they spoke about the work of the RET or lab, and approximate number of times they supplied information to that person as well as the number of times information was received from that person. Initially, teachers and GA's were provided with a complete list of all people identified by PI's, and GAs that could be expected to be present in each laboratory. After the first week of data collection, the GA list was simplified to include names of Teachers, two primary GA "mentors", PI's and "other."

Daily logs were collected via online surveys and compiled into a spreadsheet. All participants, teachers and GAs, were sent the daily survey request at the conclusion of their workday. Follow up requests were made later in the evening for non-completers in an attempt to ensure that all people submitted daily logs. Survey collection was monitored, and communication was initiated with teachers or GAs whose submissions were identified as missing or inconsistent. At the conclusion of the RET, data from each individual were compared to the other participants in that lab to identify and reconcile inconsistencies from one person to the next (for example, in a case where one day was skipped, then multiple logs were submitted on the following day, to determine which day to assign for each log).

The quantitative phase of data analysis involved a social network analysis of log data using NodeXL [16] where connections (i.e. edges) among the participants (i.e. vertices) were based upon the number of conversations they reported. All names were assigned pseudonyms and the network was visualized using the Harel-Koren fast multiscale graph (Figures $3 \& 4$ ). The qualitative phase involved a multiple case study approach where cases were bounded by the members of each laboratory. Interviews were conducted 
with 2017 members from the three case-labs with teachers and both GAs from each lab. Interviews were transcribed verbatim and coded using qualitative content analysis [17] with a code book based upon the framework in Figure 2. This analysis will be used to perform within case analysis of each of the three labs to "learn as much as possible about the contextual variables that might have a bearing on the case" [18](p. 233). Phase three of the data analysis will consist of cross case analysis in which we determine the extent to which each of the labs shares common characteristics and the extent to which each lab is unique, potentially allowing us to build "substantive theory offering an integrated framework covering multiple cases" $[18]($ p. 233).

Following the quantitative data analysis from the 2017 daily log and survey data, an interview protocol was developed in which teachers and GA's were asked to reflect upon their summer experience. Questions were crafted to collect further information about the mentoring relationships experienced by each person and asked interviewees to recall influential people in the lab, how they considered their own position in relation to the other teachers and GA's in the lab, remembered instances of mentoring given or received and they were shown a copy of the network map and were asked to comment upon the extent to which the connections illustrated were surprising, or consistent with their remembered interactions. Finally each person was asked to examine connections on the map and identify which they remembered as being mostly career based interactions and which were more psychosocial.

\section{Results}

The 2017 quantitative data resulted in a sociogram (Figure 4) in which we see two separate connected components. Nona and Julia Labs show interconnections among several of their members whereas the Senoa lab is separated from the others. This finding may be due largely to the fact that the Nona and Julia labs were both located within the same building on campus where the Senoa lab was in a separate building.
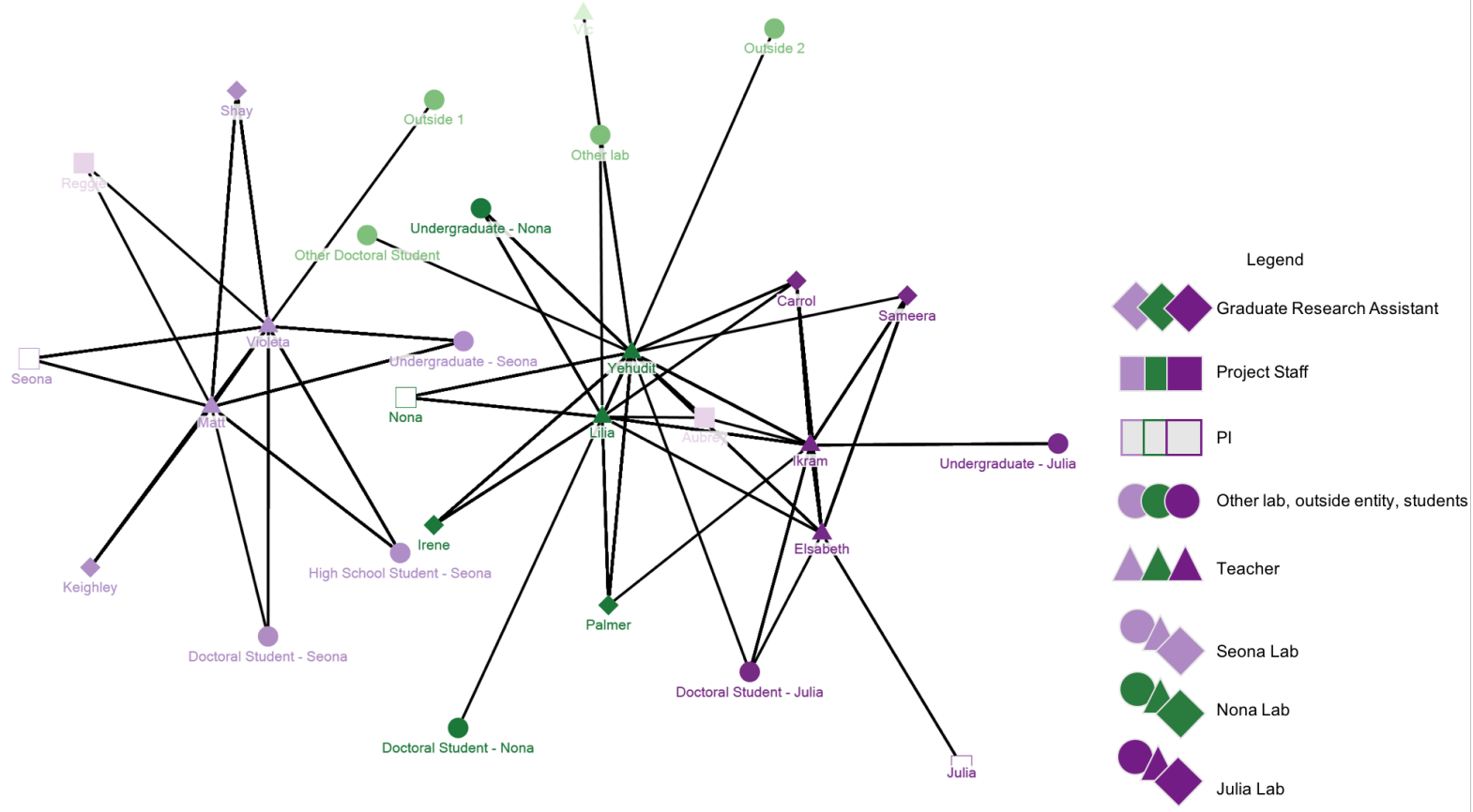

Figure 4: Sociogram illustrating the mentoring network during the summer of 2017.

Following the transcription of the interviews, a code book (Table 2) was developed based on literature characterizing mentoring functions [19], [20], [21]. And codes were applied to instances of mentoring 
described in the text. Heat maps were constructed for the total themes, and also broken out looking at teachers and GAs separately. The results show instances of both teachers and GAs describing themselves as giving and receiving mentoring, as well as instances described which were characterized as reciprocal; meaning that an interaction was one in which each member was giving and receiving mentoring. Overall, teachers were primarily characterized in the protégé role as receivers of mentoring (Table 3) whereas GAs were more strongly represented as givers of mentoring (Table 4).

Table 2: Coded themes discussed by all participants regarding mentoring during summer 2017.

\begin{tabular}{|c|c|c|c|c|}
\hline & & Giving & Reciprocal & Recieving \\
\hline \multirow{6}{*}{$\begin{array}{l}\bar{d} \\
\text { dँ } \\
\text { Uू }\end{array}$} & Coaching/training/instruction & $36 \%$ & $19 \%$ & $45 \%$ \\
\hline & Information & $36 \%$ & $3 \%$ & $62 \%$ \\
\hline & Sponsoring advancement & & & \\
\hline & Positive Exposure / Visibility & & & $100 \%$ \\
\hline & Protection & $36 \%$ & $9 \%$ & $55 \%$ \\
\hline & Challenging assignments & $50 \%$ & & $50 \%$ \\
\hline \multirow{5}{*}{ 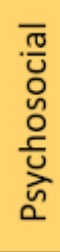 } & Acceptance/ Confirmation & $33 \%$ & $14 \%$ & $52 \%$ \\
\hline & Counseling & $29 \%$ & & $71 \%$ \\
\hline & Friendship & $20 \%$ & $60 \%$ & $20 \%$ \\
\hline & Rolemodeling & $7 \%$ & & $93 \%$ \\
\hline & Socialization "host and guide" & $50 \%$ & & $50 \%$ \\
\hline \multirow{4}{*}{$\begin{array}{l}\frac{\grave{d}}{ড} \\
\stackrel{5}{0}\end{array}$} & Other & $50 \%$ & $50 \%$ & \\
\hline & Perspective & $30 \%$ & $11 \%$ & $59 \%$ \\
\hline & Limits of Map & & & \\
\hline & Common Ground & & & \\
\hline
\end{tabular}

Table 3: Coded themes discussed by elementary teachers regarding mentoring during summer 2017.

\begin{tabular}{|c|c|c|c|c|}
\hline & & Giving & Reciprocal & Recieving \\
\hline \multirow{6}{*}{ 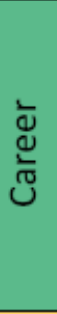 } & Coaching/training/instruction & $20 \%$ & $30 \%$ & $50 \%$ \\
\hline & Information & $33 \%$ & & $67 \%$ \\
\hline & Sponsoring advancement & & & \\
\hline & Positive Exposure / Visibility & & & $100 \%$ \\
\hline & Protection & $22 \%$ & $11 \%$ & $67 \%$ \\
\hline & Challenging assignments & & & $100 \%$ \\
\hline \multirow{5}{*}{ 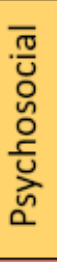 } & Acceptance/Confirmation & & & $100 \%$ \\
\hline & Counseling & $25 \%$ & & $75 \%$ \\
\hline & Friendship & $25 \%$ & $69 \%$ & $6 \%$ \\
\hline & Rolemodeling & & & $100 \%$ \\
\hline & Socialization "host and guide" & & & $100 \%$ \\
\hline \multirow{4}{*}{$\begin{array}{l}\stackrel{ \pm}{ \pm} \\
\text { ‘் }\end{array}$} & Other & & & \\
\hline & Perspective & $15 \%$ & $8 \%$ & $77 \%$ \\
\hline & Limits of Map & & & \\
\hline & Common Ground & & & $100 \%$ \\
\hline
\end{tabular}


Table 4: Coded themes discussed by GAs regarding mentoring during summer of 2017.

\begin{tabular}{|c|c|c|c|c|}
\hline & & Giving & Reciprocal & Recieving \\
\hline \multirow{6}{*}{ Uू } & Coaching/training/instruction & $50 \%$ & $8 \%$ & $42 \%$ \\
\hline & Information & $72 \%$ & $6 \%$ & $22 \%$ \\
\hline & Sponsoring advancement & & & \\
\hline & Positive Exposure / Visibility & & & \\
\hline & Protection & $100 \%$ & & \\
\hline & Challenging assignments & $88 \%$ & & $13 \%$ \\
\hline \multirow{5}{*}{ 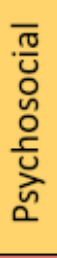 } & Acceptance/Confirmation & $58 \%$ & $25 \%$ & $17 \%$ \\
\hline & Counseling & $33 \%$ & & $67 \%$ \\
\hline & Friendship & & $25 \%$ & $75 \%$ \\
\hline & Rolemodeling & $50 \%$ & & $50 \%$ \\
\hline & Socialization "host and guide" & $100 \%$ & & \\
\hline \multirow{4}{*}{$\frac{\grave{d}}{\stackrel{c}{+}}$} & Other & $100 \%$ & & \\
\hline & Perspective & $43 \%$ & $14 \%$ & $43 \%$ \\
\hline & Limits of Map & & & \\
\hline & Common Ground & & & $100 \%$ \\
\hline
\end{tabular}

The 2018 iteration of the RET program increased in number for labs, and numbers of participants. Where there were a total of three participating labs in 2017, 2018 saw six labs hosting teachers. Daily interaction $\log$ data was collected in the same fashion as 2017 and again a sociogram was constructed to represent the reported social interactions (Figure 5). Again, the sociogram indicated that there were two connected components, with five of the six labs sharing at least one connecting relationship outside the laboratory (Nash, Everett, Ardito, Jackson and Monroe), where a single lab (Kaede)was more isolated, showing no connections to people working in other laboratories. Again it is likely that some of the interconnectedness seen among labs is based on proximity, however in the 2018 iteration, there were also reports of both teachers and GA's interacting with a program staff member conducting independent daily observations, and this person (Rhonda) also served as a bridge connecting labs to one another. 

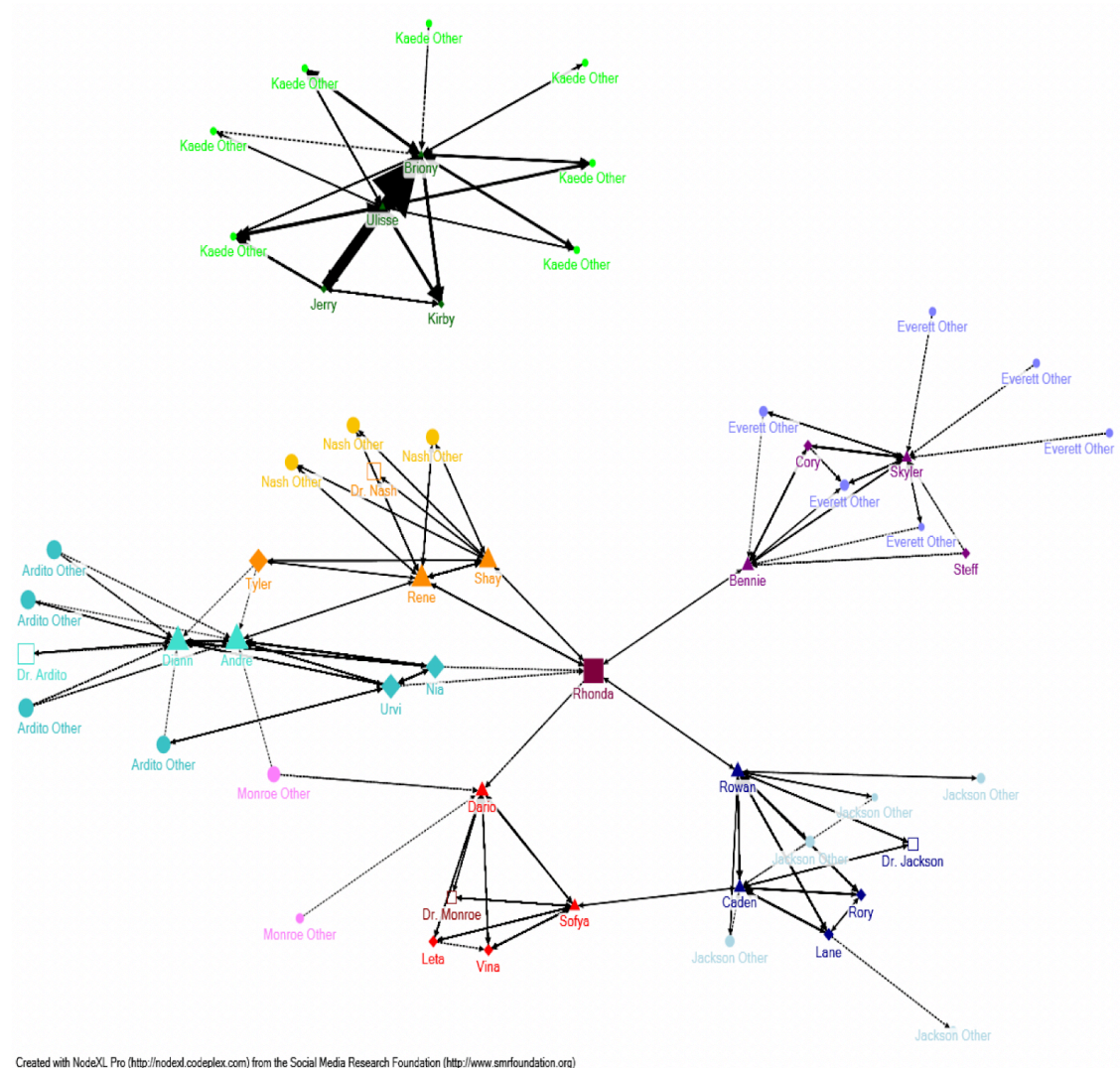

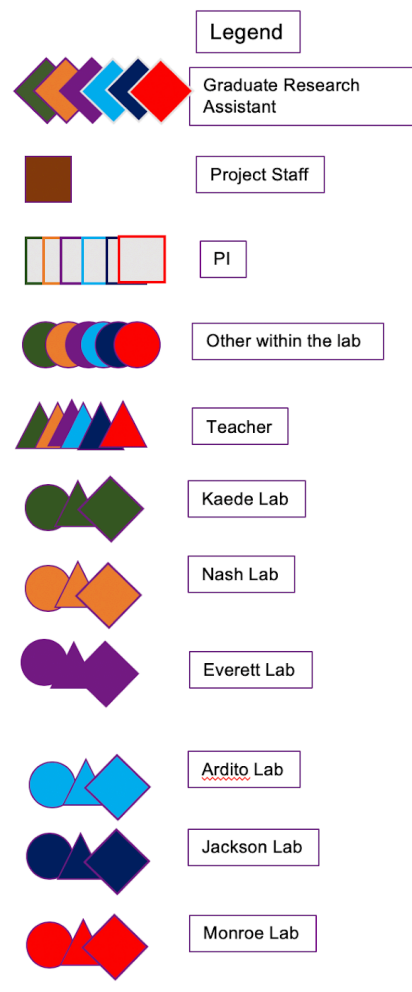

Figure 5: Sociogram illustrating the mentoring network during the summer of 2018.

\section{Discussion}

As RET programs are described and studied, teachers are the primary focus of activity, especially related to the benefits of the programs and their goals. This set of findings challenges this currently accepted assumption of teachers as the sole beneficiaries of mentoring within RET programs. We have seen that both iterations of this RET resulted in the development of interconnected, multidirectional networks of interactions between and among teachers and GA's. After conducting interviews to better characterize the nature of these interactions, our 2017 data showed that although the teachers in this study were more likely to be receiving the benefits of mentoring from the GAs in their laboratories; especially related to career development, there were also instances of GAs benefitting from mentoring received from the teachers; often in the form of psychosocial support. Having completed the sociogram construction from the 2018 data, we are preparing for our 2018 follow up interviews, and again questions will center around better understanding the nature of the interactions in terms of types and directionality of mentoring.

If demonstrated to be appropriate and transferable to the RET context within other sites, such a perspective could enhance our understanding of the experience and be used for maximizing the outcomes for all participants. 


\section{References}

[1] Caton, E., Brewer, C., \& Brown, F. (2000). Building Teacher-Scientist Partnerships: Teaching About Energy Through Inquiry. School Science and Mathematics, 100(1), 7-15.

[2] Brown, J. C., Bokor, J. R., Crippen, K. J. and Koroly, M. J. (2014) Translating Current Science into Materials for High School via a Scientist-Teacher Partnership, J. Sci. Teacher Educ., vol. 25, no. 3, pp. 239-262, 2014.

[3] Drayton, B., \& Falk, J. (2006). Dimensions that shape teacher-scientist collaborations for teacher enhancement. Science Education, 90(4), 734-761.

[4] National Science Foundation - Where Discoveries Begin, NSF - Research Experiences for Teachers (RET) in Engineering and Computer Science Active Awards | NSF - National Science Foundation. [Online]. https://www.nsf.gov/awards/award_visualization.jsp?org=NSF\&pims_id=505170\&ProgEleCode=1359 $\&$ from=fund. [Accessed: 08-Nov-2017].

[5] Tanner, K. D., Chatman, L., \& Allen, D. (2003). Approaches to Biology Teaching and Learning: Science Teaching and Learning Across the School-University Divide-Cultivating Conversations through Scientist-Teacher Partnerships. Cell Biology Education, 2(4), 195-201. doi:10.1187/cbe.03$10-0044$

[6] Blanchard, M. R., Southerland, S. A. and E. M. Granger, E. M. (2009) No silver bullet for inquiry: Making sense of teacher change following an inquiry-based research experience for teachers, Science Education, vol. 93, no. 2, pp. 322-360.

[7] Autenrieth, R. L., Lewis, C. W. and Butler-Purry, K. L. (2017) Long-Term Impact of the Enrichment Experiences in Engineering (E3) Summer Teacher Program, J. STEM Educ. Innov. Res., vol. 18, no. 1, pp. 25-31.

[8] Pop, M. M., Dixon, P., \& Grove, C. M. (2010). Research Experiences for Teachers (RET): Motivation, Expectations, And Changes to Teaching Practices Due to Professional Program Involvement. Journal of Science Teacher Education, 21(2), 127-147.

[9] Tanner, K. (2000). Evaluation of scientist-teacher partnerships: benefits to scientist participants. In 2000 NARST Annual Conference (pp. 1-33). New Orleans, LA. Retrieved from http://www.sfsesnet.org/publications/2000NARST.pdf

[10] Higgins, M. C., \& Kram, K. E. (2001). Reconceptualizing Mentoring at Work: A Development Network Perspective. The Academy of Management Review, 26(2), 264-288. https://doi.org/10.5465/AMR.2001.4378023

[11] Higgins, M., Chandler, D., \& Kram, K. E. (2008). Developmental Initiation and Developmental Networks. In B. Ragins \& K. E. Kram (Eds.), The Handbook of Mentoring at Work: Theory, Research, and Practice (pp. 349-372). Thousand Oaks: Sage Publications, Inc. https://doi.org/http://dx.doi.org/10.4135/9781412976619.n14

[12] Yip, J., \& Kram, K. (2015). Developmental Networks : Enhancing the Science and Practice of Mentoring. DRAFT (for the SAGE Handbook of Mentoring), (July), 1-38.

[13] (McKinsey, 2016)

[14] Eby, L. T. d. T., Allen, T. D., Hoffman, B. J., Baranik, L. E., Sauer, J. B., Baldwin, S., . . Evans, S. C. (2013). An interdisciplinary meta-analysis of the potential antecedents, correlates, and consequences of protégé perceptions of mentoring. Psychological Bulletin, 139(2), 441-476. doi:10.1037/a0029279

[15] Creswell, J. W. (2014). Research Design: Qualitative, Quantitative and Mixed Methods Approaches (4th. ed.): Sage.

[16] Hansen, D., Shneiderman, B., \& Smith, M. A. (2010). Analyzing Social Media Networks with NodeXL: Insights from a Connected World: Morgan Kaufmann.

[17] Vaismoradi, M., Turunen, H., \&Bondas, T. (2013). Content analysis and thematic analysis: Implications for conducting a qualitative descriptive study. Nurs. Heal. Sci., vol. 15, no. 3, pp. 398405. 
[18] Merriam, S. B. \& Tisdell, E. J. (2016). Conducting Effective Interviews in Qualitative Research: A Guide to Design and Implementation, Fourth., Jossey-Bass, pp. 107-136.

[19] Ragins, B. R., Kram, K. E., \& Roosevelt, E. (2007) "Meaning of Mentoring," in The Handbook of Mentoring at Work: Theory, Research, and Practice, 2007, pp. 3-15.

[20] Noe, R. A. (1988). An investigation of the determinants of successful assigned mentoring relationships. Personnel psychology, 41(3), 457-479.

[21] Blackwell, J. E. (1989). Mentoring: An action strategy for increasing minority faculty. Academe, 75(5), 8-14. 